\title{
CARACTERIZAÇÃO ANATÔMICA DA MADEIRA DE SETE ESPÉCIES DA AMAZÔNIA COM VISTAS À PRODUÇÃO DE ENERGIA E PAPEL ${ }^{(1)}$
}

\begin{abstract}
José Elias de PAULA(2)
Resumo - Foram estudadas as características anatômicas da madeira de 7 espécies ocorrentes na floresta Amazônia com vistas a geração de energia ou produção de papel. Para qualificação de madeira para produção de papel consideraram-se, dentre outros parâmetros, o coeficiente de rigidez e de flexibilidade, densidade, índice de Runkel, percentual de fibras, vasos, parênquima axial e de raios. Para produção de energia determinaram-se a densidade, a fração parede (\%) das células em relação a área ocupada por cada tipo de células, percentual de fibras, de vasos e de parênquima axial e radial. $\mathrm{O}$ estudo foi baseado em 3 áreas de seções transversais, orientadas do centro em direção ao alburno. Com base nas características anatômicas e na densidade, Bellucia grossularioides, Cecropia palmata, Duguetia cauliflora, Eschweilera matamata e Parkia multuijuga podem ser usadas para polpa destinada a produção de papel, e Myrocarpus frondosus, Sloanea grandis podem ser usadas na produção de carvão.
\end{abstract}

Palavras - chave: Madeiras da Amazônia, Anatomia, Energia, Papel.

\section{Anatomical caracterization of seven woods from Amazonia for energy and paper production}

\begin{abstract}
The wood anatomy of 7 species from the Brazilian Amazon forest was studied to evaluate them for energy production (charcoal and alcohol) and for paper production. Transverse. For paper production, the wood was qualified according to the coefficient of rigidity and flexibility, density, Runkel index, the percent of fibers, vessel, axial parenchyma and percent of area occupied by rays. For energy production, wall fraction in relation to the area occupied by cells (\%), percent of fibers, vessel, and both axial and ray parenchyma, as well as wall density were considered. The study was based on 3 areas of the cross section of the trunk, from the center towards the sapwood. On the basis of anatomy and density, Bellucia grossularioides, Cecropia palmata, Duguetia cauliflora, Eschweilera matamata and Parkia multijuga can be used for pulp for paper production, and Myrocarpus frondosus, Sloanea grandis can be used for charcoal production.
\end{abstract}

Key-words: Amazon woods, Anatomy, Energy, Paper.

\section{INTRODUÇAO}

A Amazônia ainda é o maior bioma da Terra, não obstantes as ações antrópicas negativas a que tem sido submetida nas últimas décadas. Aí está a maior área florestal do mundo, representada por uma grande variedade de ecossistemas. Milhares de formas de vida componentes dos ecossistemas amazônicos têm sido objeto de estudo por um universo de pesquisadores nacionais e de outros países. $\mathrm{O}$ estudo dos taxa constantes deste artigo se situa dentro do contexto de geração de conhecimentos referentes às formas de vida da região amazônica.

\footnotetext{
${ }^{1}$ Trabalho realizado com apoio do CNPq.

${ }^{2}$ Bolsista do CNPq, Universidade de Brasília, Departamento de Botânica, CEP:70.910-900, Brasília, Distrito Federal - Brasil, e-mail: eliaspaula@bol.com.br
} 
Loureiro \& Silva (1968) realizaram estudos dendrológicos, macroscópicos da madeira e distribuição de 117 espécies da Amazônia, onde salientam o uso da madeira de cada espécie. Overbeck (1968) estudou a madeira de 12 espécies da Amazônia e concluiu que todas podem ser utilizadas para fabricação papel. Overbeck (1968), Corrêa et al. (1970), Corrêa et al. (1974) e Corrêa (1985) foram praticamente os primeiros a estudarem espécies ocorrentes na Amazônia visando à produção de papel, tendo como resultados a produção de folhas de papel com características físicas de excelente qualidade.

Nesse sentido abordaram-se no presente estudo aspectos anatômicos da madeira de 7 espécies da mencionada Região, com o objetivo de informar as características estruturais anatômicas capazes de orientar o uso mais adequado da madeira de cada espécie, principalmente para geração de energia e produção de papel. Por outro lado, qualquer fenômeno físico que possa ocorrer na madeira durante o beneficiamento, tratamento e uso, bem como apodrecimento rápido, pode ser explicado em parte com base no conhecimento anatômico da madeira (Silva Júnior et al., 1993; Paula \& Alves, 1997; Paula, 1989)

O estudo anatômico da madeira tem sido realizado na sua grande maioria como respaldo e subsídio à Taxonomia e em pequena escala relacionado com a Fisiologia e Ecologia. Porém o objetivo deste trabalho é a qualificação de madeira para geração de energia (carvão, lenha, álcool combustível, coque metalúrgico) e produção de papel. Com esse enfoque, são considerados aqui parâmetros anatômicos que dizem respeito à qualificação de madeira para fins energéticos e produção de papel, dispensando-se portanto, aspectos puramente descritivos. Por exemplo, no que concerne a qualificação de madeira para geração de energia ou para produção de papel, não é importante se o parênquima axial seja paratraqueal ou apotraqueal. No contexto de nosso objetivo ele é considerado em termos de quantidade.

O conhecimento da estrutura anatômica da madeira é de fundamental importância no que tange à sua qualificação para atender a grande variedade de usos, evitando-se emprego inadequado e desperdício. É pois dentro desse contexto que se situa o estudo em apreço.

\section{MATERIAL E MÉTODOS}

As madeiras utilizadas neste estudo e o material botânico fértil que serviu para a identificação científica de cada espécie foram coletadas e identificadas pelo autor. As amostras circulares (discos) dos troncos foram colhidas na altura do DAP (1,30 $\mathrm{m}$ do solo), de árvores com mais de 15 anos de idade. $\mathrm{O}$ material botânico fértil foi incorporado ao acervo do Herbário da Universidade de Brasília (UB), sob número de coleta, e a madeira incorporada à xiloteca do Departamento de Botânica dessa Universidade, conforme discriminação que se segue.

1. Bellucia grossularioides (L.) Triana (Melastomataceae), goiaba-de-anta, município de Rondon (Pará); col. J. Elias de Paula 3507 (UB), Xiloteca 219.

2. Cecropia palmata Willd. (Cecropiaceae), imbaúba-branca, município de Santa Quitéria (Maranhão); col. J. Elias de Paula 3518 (UB), Xiloteca 317

3. Duguetia cauliflora R. E. Fries (Annonaceae), envira, município de Almerim (Pará), Distrito de Monte Dourado, rio Jari; col. J. Elias de Paula 3465 (UB), Xiloteca 299.

4. Eschweilera matamata Huber (Lecythidaceae), estopeira, município de Tucurui (Pará); col. J. Elias de Paula 3534 (UB), Xiloteca 342.

5. Myrocarpus frondosus F. All. (Fabaceae), roxinho, município de Tucurui (Pará); col. J. Elias de Paula 3535 (UB), Xiloteca 321.

6. Parkia multijuga Benth. (Mimosaceae), faveira, município de ParauapebaCarajás (Pará); col. J. Elias de Paula 3522 (UB), Xiloteca 338.

7. Sloanea grandis Ducke (Elaeoscarpaceae), urucurana, município de Almerim (Pará), Distrito de Monte Dourado, rio Jari; col. J. Elias de Paula 3519 (UB), Xiloteca 219.

Os corpos de prova para obtenção dos cortes histológicos e determinação da densidade foram obtidos de amostras em forma de cunha 
(Fig.1) de áreas disjuntivas, orientadas radialmente do centro em direção ao alburno, denominadas área 1 (centro, incluindo o lenho juvenil), área 2 (terço médio) e área 3 (alburno), sendo que para Eschweilera matamata e Sloanea grandis, por ser de diâmetro acima de $90 \mathrm{~cm}$, consideraram-se 4 áreas. A espessura dos cortes histológicos variou entre 20 e $40 \mu \mathrm{m}$. Em todos os casos incluiu-se o lenho juvenil, que é o primeiro a se forma quando cessa o crescimento primário e representa a parte mais interna da madeira (área $1 \mathrm{da}$ figura 1), formado portanto, quando a árvore tinha pouca idade, enquanto que nas demais áreas amostradas (Figura 1), o lenho é mais novo em relação ao da área 1 (lenho juvenil), porém formado quando a árvore tinha mais idade.
A contagem de vasos por $\mathrm{mm}^{2}$, bem como dos raios por mm linear foi feita em microscópio tendo câmara clara acoplada e com a escala micrométrica objetiva de um $\mathrm{mm}$ construiu-se uma área correspondente a $1 \mathrm{~mm}^{2}$, utilizando cortes transversais e tangenciais, respectivamente, sendo que a média foi baseada em 25 amostragens.

Mediram-se a espessura da parede celular, o diâmetro dos vasos, das fibras, das células parenquimatosas, bem como a largura e a altura dos raios, além do comprimento das fibras e dos elementos de vasos, usando-se uma escala ocular com fator de correlação conhecido. Os dados estatísticos constantes das tabelas 1 a 7 foram determinados com base em 25 amostragens para cada parâmetro.

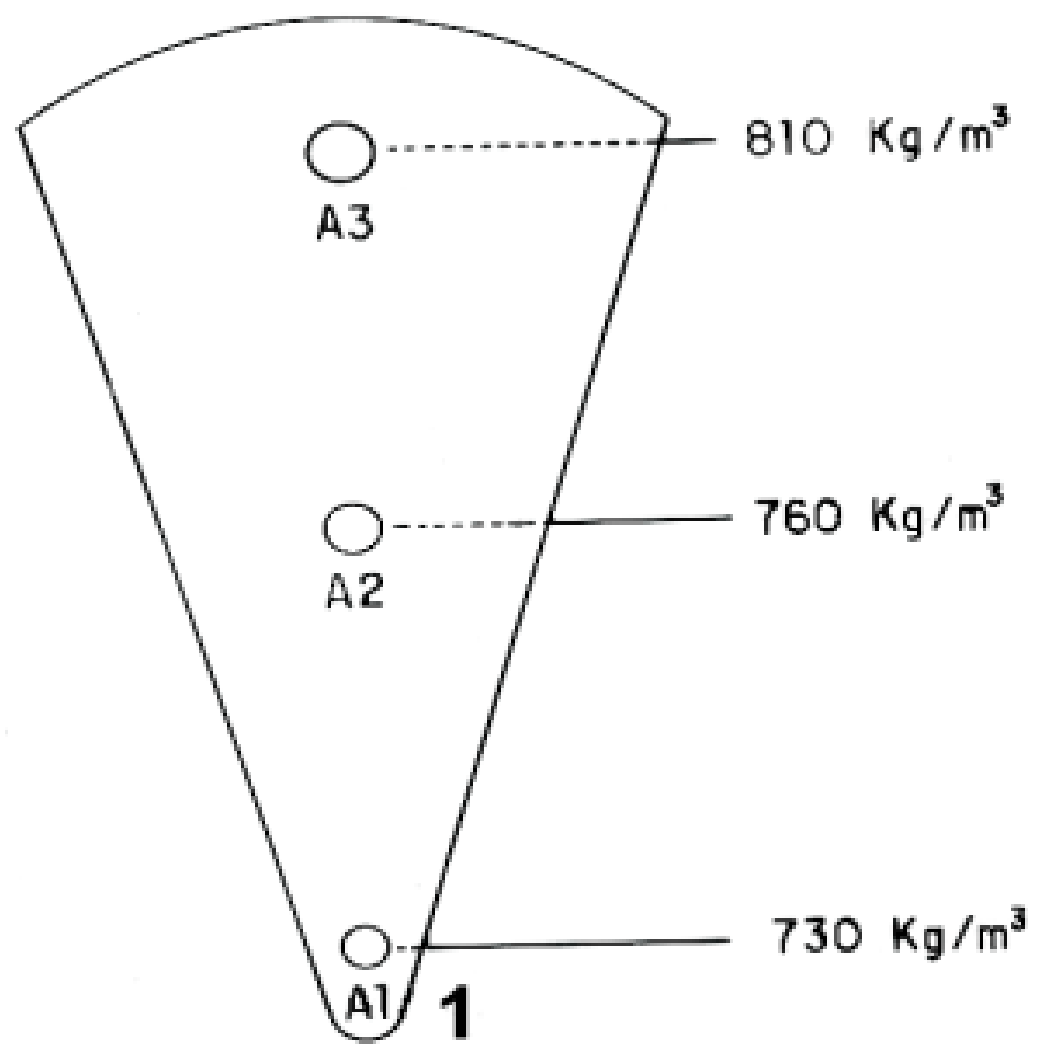

Figura 1. Myrocarpus frondosus: desenho esquemático da madeira mostrando o aumento da densidade, partindo do centro (lenho juvenil) em direção ao alburno. 
A fração parede dos elementos celulares foi determinada usando-se a fórmula 100.2e/D, onde (e) representa a espessura da parede celular, inclusive das fibras, (D) o diâmetro total, com o valor apresentado em percentagem (Salgiya, 1972; Foelkel \& Barrichelo, 1975; Paula \& Alves, 1997). Esse parâmetro indica o espaço ocupado pela parede em relação ao espaço total ocupado por cada célula.

Determinou-se o coeficiente de rigidez das fibras pela razão percentual do diâmetro do lume (d) sobre o diâmetro total (D): 100.d/ D. Esse parâmetro indica o grau de colapso que as fibras sofrem durante o processo de fabricação de papel, pois quanto mais alto, maior será o grau de colapso.

$O$ índice de Runkel das fibras foi estimado pela razão de duas vezes a espessura da parede sobre o diâmetro do lume: $2 \mathrm{e} / \mathrm{d}$. Ressalta-se que o diâmetro do lume é igual ao diâmetro total, menos duas vezes a espessura da parede (D-2e). Runkel, (1952) com base nesse índice, estabeleceu os seguintes grupos: grupo I - até 0,25 a fibra é considerada excelente para papel; grupo II - de 0,25-0, 50 , muito boa para papel; grupo III - de 0,50 1, boa para papel; grupo IV - de 1,0-2,0, regular para papel; grupo $\mathrm{V}$ - acima de 2,0 não deve ser usada para papel, tendo em vista que o grau de colapso é muito baixo. Na prática o índice de Runkel tem o mesmo valor em relação ao coeficiente de rigidez (Moreschi, 1975).
O coeficiente de flexibilidade, também conhecido por índice de feltragem, foi determinado pela relação do comprimento (L) da fibra sobre a largura (W): L/W. Esse referencial indica a capacidade de as fibras formarem feltro (Moreschi, 1975)

$O$ percentual de parênquima axial, de raios, de fibras e de vasos foi determinado utilizando-se fotomicrografias de cortes transversais, com áreas conhecidas e com um planímetro efetuaram-se as leituras das áreas ocupadas por cada componente estrutural, também pelo método de pesagem do papel das áreas ocupadas por cada tipo celular existente na fotomicrografia. A média dos dois métodos (leitura e pesagem) é apresentada nas tabelas 1 a 7 .

Adotou-se a terminologia recomendada por IAWA (1989) e Comissão Panamericana de Normas Técnicas (1974). As fotomicrografias ilustrativas foram obtidas no fotomicroscópio Zeis. Para cada aumento foi fotografada a escala micrométrica objetiva correspondente que consta das respectivas fotos.

\section{RESULTADOS}

1. Bellucia grossularioides (tabela 1; figuras 2, 3 e 4). Vasos- de distribuição difusa, solitários, geminados e múltiplos radiais de

Tabela 1. Bellucia grossularioides - densidade e parâmetros anatômicos quantitativos dos elementos constituintes da madeira para análise de qualidade

\begin{tabular}{|c|c|c|c|}
\hline Parâmetros mensurados & Área 1 & Área 2 & Área 3 \\
\hline Vasos Diâmetro $(\mu \mathrm{m})$ & $131,47 \pm 25,37$ & $137,36 \pm 31,67$ & $146,18 \pm 24,95$ \\
\hline Quantidade (/mm2) & $5,28 \pm 1,49$ & $3,50 \pm 0,96$ & $3,68 \pm 0,99$ \\
\hline Fração parede (\%) & 3,50 & 5,26 & 9,68 \\
\hline Área ocupada (\%) & 17,85 & 19,46 & 18,23 \\
\hline \multicolumn{4}{|l|}{ Raios } \\
\hline Altura $(\mu \mathrm{m})$ & $431,20 \pm 21,38$ & $470 \pm 228,44$ & $346,40 \pm 149,61$ \\
\hline Largura $(\mu \mathrm{m})$ & $10,47 \pm 2,63$ & $20,88 \pm 2,29$ & $20,52 \pm 289$ \\
\hline Quantidade (/mm) & $7,20 \pm 2,44$ & $10,70 \pm, 83$ & $9,40 \pm 2,91$ \\
\hline Área ocupada (\%) & 7,90 & 17,80 & 18,23 \\
\hline \multicolumn{4}{|l|}{ Fibras } \\
\hline Diâmetro total $(\mu \mathrm{m})$ & 20,70 & 18,40 & 20,70 \\
\hline Comprimento $(\mu \mathrm{m})$ & $735,60 \pm 227,09$ & $721,20 \pm 185,86$ & $768 \pm 176,49$ \\
\hline Espessura da parede(\%) & 2,30 & 2,99 & 4,60 \\
\hline Largura $(\mu \mathrm{m})$ & $21,53 \pm 3,38$ & $21,34 \pm 3,29$ & $21,71 \pm 2,66$ \\
\hline Fração parede (\%) & 22,22 & 32,50 & 32,50 \\
\hline Coef. flexiblidade(\%) & 34,17 & 33,80 & 35,31 \\
\hline Coef. de rigidez (\%) & 77,78 & 67,50 & 55,56 \\
\hline Índice de Runkel & 0,29 & 0,48 & 0,80 \\
\hline Grupo de Runkel & 1 & ॥ & II \\
\hline Quantidade (\%) & 53,68 & 55,21 & 58,55 \\
\hline Parênquima axial (\%) & 20,57 & 7,70 & 9,46 \\
\hline Densidade seca $(\mathrm{kg} / \mathrm{m} 3)$ & 610 & 700 & 640 \\
\hline Densidade básica $(\mathrm{kg} / \mathrm{m} 3)$ & 510 & 650 & 600 \\
\hline
\end{tabular}




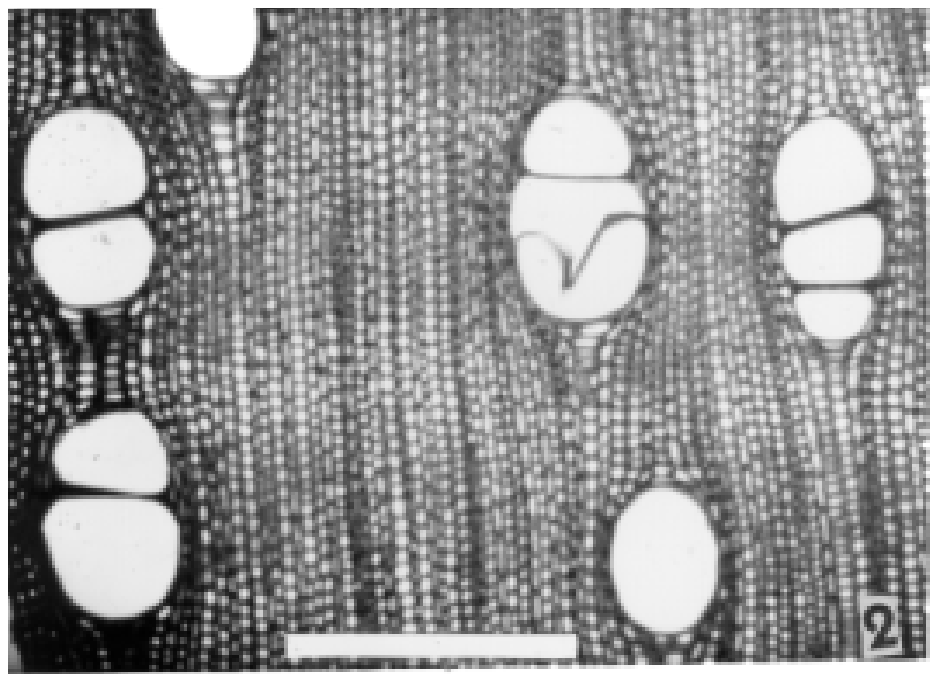

Figura 2 - Bellucia grossularioides: corte transversal mostrando abundância de fibras e ausência de parênquima axial; escala de $200 \mu \mathrm{m}$.

até 5 elementos, sem predominância de nenhum dos tipos nas 3 áreas, sendo pouco numerosos, de tamanho médio nas 3 áreas; na área 1 o diâmetro variou de 104 a $149 \mu \mathrm{m}$, na área 2 de 118 a $157 \mu \mathrm{m}$ e na área 3 entre 127 e 164 $\mu \mathrm{m}$. Elementos de vaso, com placa de perfuração simples, apresentam apêndices curtos numa ou nas duas extremidades. Pontuações intervasculares alternas, areoladas, com abertura inclusa; fração parede baixa nas 3 áreas; o comprimento médio dos elementos de vaso na área 1 foi de 131,79 $\mu \mathrm{m}$, variando entre 120 e 158 , na área 2 foi de $166 \mu \mathrm{m}$, variando de 141 a 289 e na área 3 foi de $147 \mu \mathrm{m}$, com intervalos de variação entre 131 e $168 \mu \mathrm{m}$, cuja largura média da área 1 foi de $138 \mu \mathrm{m}$, variando entre 129 e 147 $\mu \mathrm{m}$, na área 2 a média foi de $149 \mu \mathrm{m}$, variando de 139 a $161 \mu \mathrm{m}$ e na área 3 a média foi de $162 \mu \mathrm{m}$, variando de 149 a 178 $\mu \mathrm{m}$. Parênquima axial - ausente. Raios- são todos uniseriados, altura variando de 49 a 103 $\mu \mathrm{m}$ e a largura entre 5 e $13 \mu \mathrm{m}$. Fibrasabundantes, muito curtas, na área 10 comprimento variou entre 721 e $838 \mu \mathrm{m}$, na área 2, de 694 a $893 \mu \mathrm{m}$ e na área 3 a variação foi de 698 e $878 \mu \mathrm{m}$. Fibras gelatinosas (Figura 4) ocorrem apenas na área 3.

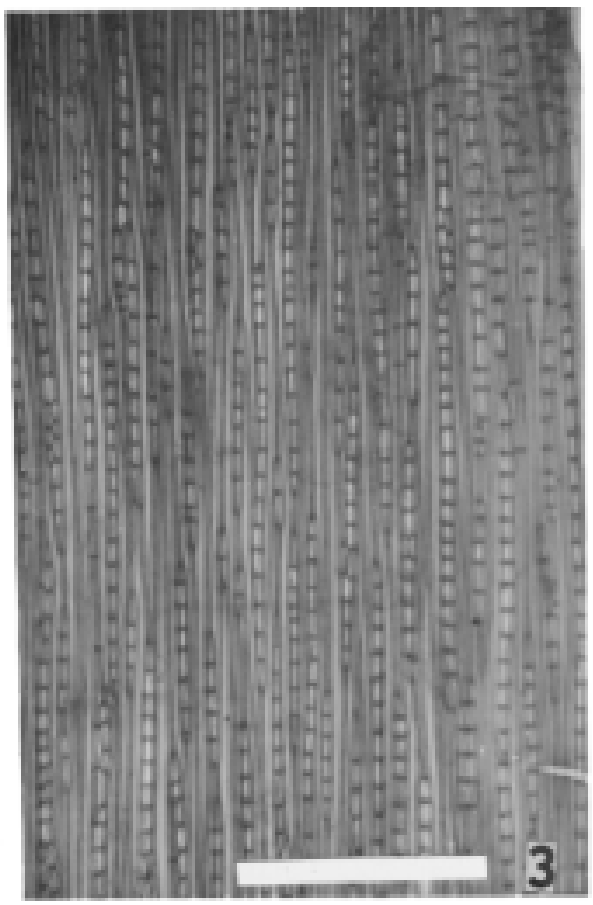

Figura 3 - Bellucia grossularioides: corte tangencial evidenciando raios uniseriados; escala de $200 \mu \mathrm{m}$. 


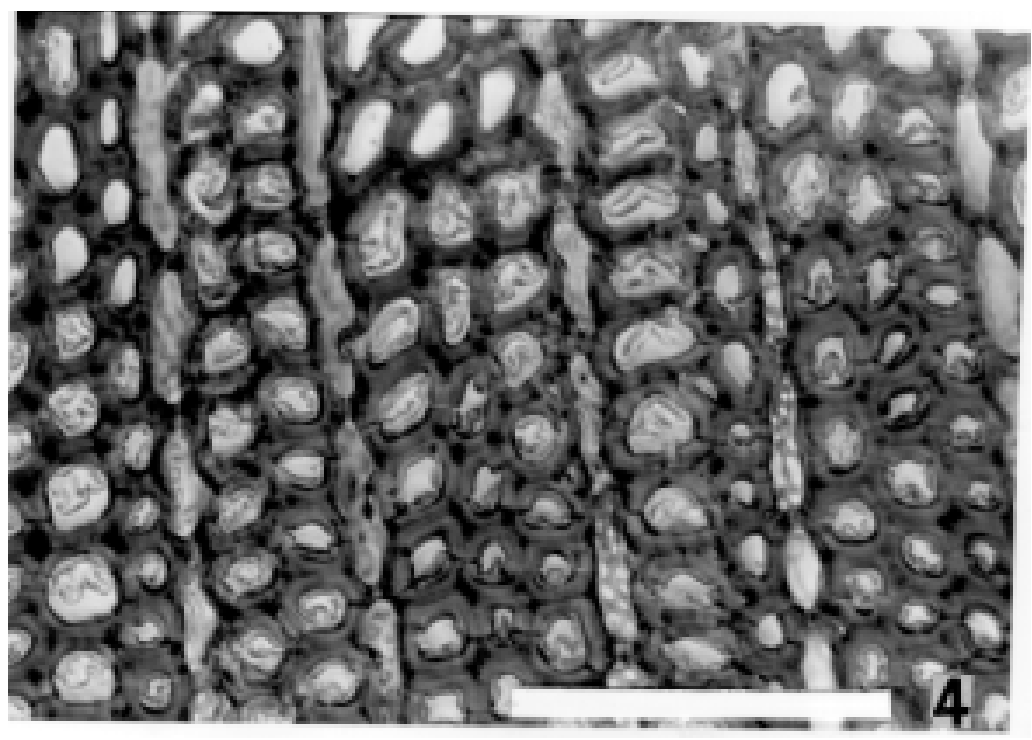

Figura 4 - Bellucia grossularioides: corte transversal mostrando fibras gelatinosas; escala de $200 \mu \mathrm{m}$.

2. Cecropia palmata (tabela 2, figuras 5 e 6). Vasos- distribuição difusa, predominantemente solitários, ocorrendo também geminados e múltiplos radiais de até 4 elementos, de tamanho médio nas áreas 1 e 2 e na área 3, grande; muito pouco nas 3 áreas; fração parede extremamente baixa nas 3 áreas (tabela 2). Elementos de vaso com placa de perfuração simples, terminal e total, o comprimento médio na área 1 foi de $425 \mu \mathrm{m}$, variando de 250 a $600 \mu \mathrm{m}$, na área 2 foi de $379 \mu \mathrm{m}$, variando de 353 a $397 \mu \mathrm{m}$, na área 3 a medida foi de $412 \mu \mathrm{m}$, variando de 389 e 447 $\mu \mathrm{m}$, e a largura média na área 1 foi de $202 \mu \mathrm{m}$, variando entre 102 e $320 \mu \mathrm{m}$, na área 2 foi de $216 \mu \mathrm{m}$, variando entre 218 e $228 \mu \mathrm{m}$, na área 3 a média foi de $218 \mu \mathrm{m}$, variando entre $198 \mathrm{e}$ $232 \mu \mathrm{m}$. Pontuações intervasculares alternas, areoladas, com abertura inclusa. Parênquima axial - ausente. Raios - homogêneos, constituídos de células procumbentes, 1-2 seriados na área 1 , na área 2 predominam os 3 seriados, ocorrendo também 2 seriados e na área 3 predominam os 5-6 seriados. A fração parede das células radiais foi $12,5 \%, 13,3 \%$ e $16, \%$, respectivamente nas áreas 1,2 e 3 . A média

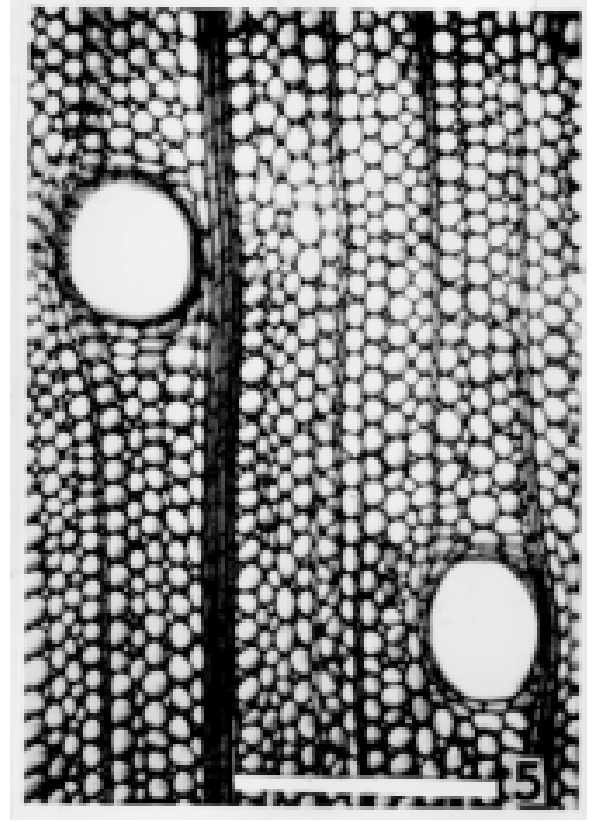

Figura 5 - Cecropia palmata: corte transversal mostrando abundância de fibras de parede fina; escala de $200 \mu \mathrm{m}$. 
Tabela 2 - Cecropia palmata - densidade e parâmetros anatômicos quantitativos dos elementos constituintes da madeira para análise de qualidade

\begin{tabular}{|c|c|c|c|}
\hline Parâmetros mensurados & Área 1 & Área 2 & Área 3 \\
\hline \multicolumn{4}{|l|}{ Vasos } \\
\hline Diâmetro $(\mu \mathrm{m})$ & $135 \pm 16,4$ & $136 \pm 26$ & $210 \pm 34$ \\
\hline Quantidade(/mm2) & $2 \pm 0,6$ & $1,5 \pm 0,5$ & $1,4 \pm 0,7$ \\
\hline Fração parede (\%) & 3,4 & 3,5 & 4 \\
\hline Área ocupada (\%) & 8,8 & 8,5 & 7,8 \\
\hline \multicolumn{4}{|l|}{ Raios } \\
\hline \multicolumn{4}{|l|}{ Altura $(\mu \mathrm{m})$} \\
\hline 4-seriados & $760 \pm 214$ & $1000 \pm 318$ & $1000 \pm 210$ \\
\hline 5 -seriados & $1100 \pm 305$ & $1603 \pm 400$ & $1475 \pm 415$ \\
\hline 6 -seriados & $470 \pm 141,4$ & $390 \pm 86$ & $1770 \pm 4$ \\
\hline \multicolumn{4}{|l|}{ Largura $(\mu \mathrm{m})$} \\
\hline 4-seriados & $41 \pm 8$ & $42 \pm 7,8$ & $80 \pm 12$ \\
\hline 5 -seriados & $38 \pm 8,9$ & $54 \pm 5,1$ & $105 \pm 12,5$ \\
\hline 6 -seriados & $33 \pm 5$ & $34 \pm 9$ & $125 \pm 20$ \\
\hline \multicolumn{4}{|l|}{ Quantidade (/mm) } \\
\hline 4 -seriados & $3 \pm 1,5$ & $1,4 \pm 0,76$ & $0,5 \pm 0,19$ \\
\hline 5 -seriados & $1,3 \pm 1,26$ & $2,3 \pm 1,05$ & $1,4 \pm 0,70$ \\
\hline 6 -seriados & $2,5 \pm 1,5$ & $1,6 \pm 1,06$ & $1,2 \pm 0,7$ \\
\hline Área ocupada (\%) & 13 & 12,5 & 15,30 \\
\hline \multicolumn{4}{|l|}{ Fibras } \\
\hline Diâmetro total $(\mu \mathrm{m})$ & 30 & 26 & 28,5 \\
\hline Comprimento $(\mu \mathrm{m})$ & $888,5 \pm 172,5$ & $73 \pm 242,5$ & $1511 \pm 274$ \\
\hline Espessura da parede $(\mu \mathrm{m})$ & 2,5 & 2,4 & 4,6 \\
\hline Largura $(\mu \mathrm{m})$ & $58 \pm 1,05$ & $48 \pm 0,8$ & $30 \pm 0,7$ \\
\hline Fração parede (\%) & 15,30 & 17,4 & 32 \\
\hline Coef. Flexibilidade (\%) & 177,5 & 214 & 604 \\
\hline Coef. rigidez (\%) & 84,7 & 84,6 & 6 \\
\hline Índice de Runkel & 0,18 & 0,21 & 0,38 \\
\hline Grupos de Runkel & 1 & । & ॥ \\
\hline Área ocupada (\%) & 78,2 & 79 & 79,9 \\
\hline Parênquima axial (\%) & 0 & 0 & 0 \\
\hline Densidade seca $\left(\mathrm{kg} / \mathrm{m}^{3}\right)$ & 256 & 263 & 475 \\
\hline Densidade básica $\left(\mathrm{kg} / \mathrm{m}^{3}\right)$ & 249 & 258 & 466 \\
\hline
\end{tabular}

das 3 áreas foi de 1,9 raios por mm. Fibras abundantes nas 3 áreas, de parede fina em relação à área ocupada por cada célula, cujo comprimento variou de 713 a $758 \mu \mathrm{m}$ na área 1, entre 708 e $763 \mu \mathrm{m}$ na área 2 e de 742 a 796 $\mu \mathrm{m}$ na área 3 .

3. Duguetia cauliflora (tabela 3; figuras 7 e 8). Vasos- Distribuição difusa nas 3 áreas; na área 1 são solitários, geminados e múltiplos radiais de até 5 elementos, raramente múltiplos em cachos de até 6 elementos, sendo que os solitários são os predominantes; na área 2 predominam os vasos geminados, ocorrendo também solitários e múltiplos radiais de até 4 elementos, às vezes em cachos com até 4 vasos. O diâmetro tangencial menor foi da área 1 , com $117 \mu \mathrm{m}$ em média, na área 2 a média foi de $134 \mu \mathrm{m}$ e na área 3 de $135 \mu \mathrm{m}$, poucos por $\mathrm{mm}^{2}$ nas 3 áreas.. A fração parede dos vasos foi de 7,46\%, 5,8\% e 9,9\%, respectivamente para área 1,2 e 3 . Elementos de vasoraramente com apêndice em uma das extremidades, placa de perfuração múltipla, total e terminal nas 3 áreas, na área 10

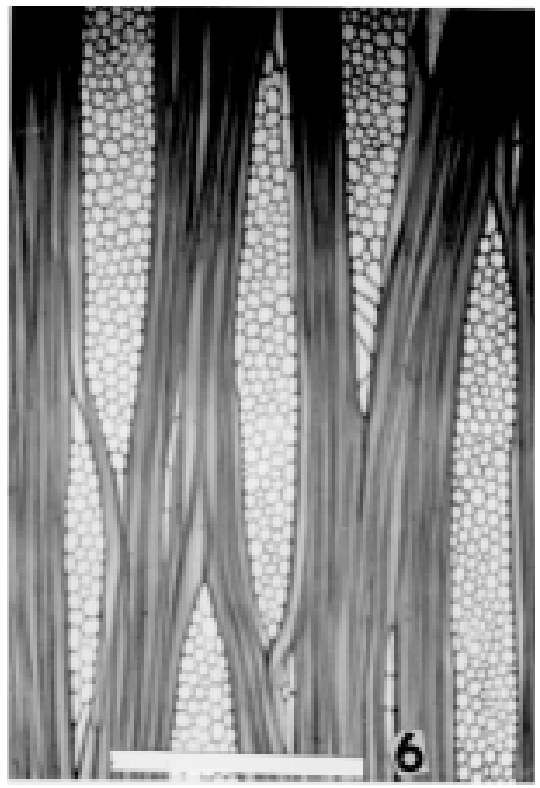

Figura 6 - Cecropia palmata: corte tangencial evidenciando raios multiseriados; escala de $200 \mu \mathrm{m}$. 
comprimento médio foi de $512 \mu \mathrm{m}$, variando entre 470 e $580 \mu \mathrm{m}$, na área 2 foi de $390 \mu \mathrm{m}$ com intervalo de variação de 360 a $411 \mu \mathrm{m}$ e na área 3 a média foi de 460 a $530 \mu \mathrm{m}$. Quanto à largura, a média das 3 áreas foi de 148 na área 1 a variação foi de 100 a $130 \mu \mathrm{m}$, na área 2 de 80 a $150 \mu \mathrm{m}$ e na área 3 a variação foi de 120 a $180 \mu \mathrm{m}$. Pontuações intervasculares, areoladas, alternas, com abertura inclusa. Parênquima axial- pouco, apotraqueal, subagregado, em faixas curtas e estreitas, dispostas entre os raios, com duas camadas de células na largura. Camadas de crescimento aparecem em algumas partes das 3 áreas. A fração parede das células desse parênquima foi de $20 \%$ na área 1 , na área $2(20 \%)$ e na área 3 (26,66 \%). Raios - homogêneos nas 3 áreas, constituídos de células procumbentes. $\mathrm{Na}$ área
1 os raios são 2-3 seriados e nas áreas 2 e 3 são 2-4 seriados; fração parede das células radiais foi de $16 \%, 25 \%$ e $25,5 \%$, respectivamente nas áreas 1,2 e 3; a altura dos raios 2 -seriados da área 1 variou entre 170 e $370 \mu \mathrm{m}$, a dos 3-seriados variou entre 410 e $960 \mu \mathrm{m}$, enquanto que a altura dos raios 4-seriados variou de 609 a $648 \mu \mathrm{m}$; na área 1 a largura dos raios 2-seriados variou entre 20 e $40 \mu \mathrm{m}$, dos 3-seriados a variação foi de 30 a $60 \mu \mathrm{m}$, dos 4-seriados variou de 50 a $70 \mu \mathrm{m}$. Fibras- abundantes, muito curtas na área 1, variando de 762 a $844 \mu \mathrm{m}$ e curtas nas áreas 2 e 3, na área 2 variou entre 1012 e $1096 \mu \mathrm{m}$ e na área 3 a variação foi de 1034 a $1086 \mu \mathrm{m}$, de parede muito fina na área 1 em relação ao espaço ocupado e fina nas áreas 2 e 3.

Tabela 3 - Duguetia cauliflora - densidade e parâmetros anatômicos quantitativos dos elementos constituintes da madeira para análise de qualidade

\begin{tabular}{|c|c|c|c|}
\hline Parâmetros mensurados & Área 1 & Área 2 & Área 3 \\
\hline \multicolumn{4}{|l|}{ Vasos } \\
\hline Diâmetro $(\mu \mathrm{m})$ & $117 \pm 27$ & $134 \pm 21$ & $136 \pm 23$ \\
\hline Fração parede (\%) & 7,46 & 5,8 & 5,3 \\
\hline Quantidade (/mm2) & $3,8 \pm 1,5$ & $3,4 \pm 1$ & $3 \pm 0,9$ \\
\hline Área ocupada (\%) & 9,7 & 8,6 & 8,3 \\
\hline \multicolumn{4}{|l|}{ Raios } \\
\hline \multicolumn{4}{|l|}{ Altura $(\mu \mathrm{m})$} \\
\hline 2-seriados & $512 \pm 174,5$ & $325 \pm 76$ & \\
\hline 3-seriados & $738 \pm 186,5$ & $827 \pm 118$ & \\
\hline 4-seriados & & $625 \pm 135$ & \\
\hline \multicolumn{4}{|l|}{ Largura $(\mu \mathrm{m})$} \\
\hline 2 -seriados & $25 \pm 7,8$ & $22 \pm 5,09$ & \\
\hline 3-seriados & $35 \pm 7,8$ & & \\
\hline 4-seriados & & $49 \pm 10$ & $37 \pm 6$ \\
\hline \multicolumn{4}{|l|}{ Quantidade (/mm) } \\
\hline 2-seriados & $2,3 \pm 1,16$ & $0,9 \pm 0,56$ & \\
\hline 3-seriados & $3,2 \pm 0,30$ & $2,5 \pm 1,26$ & \\
\hline 4-seriados & & $1,3 \pm 1,05$ & $1,3 \pm 1,05$ \\
\hline Área ocupada (\%) & 17,3 & 11,4 & 9,7 \\
\hline \multicolumn{4}{|l|}{ Fibras } \\
\hline Diâmetro total $(\mu \mathrm{m})$ & 16 & 18 & 20 \\
\hline Espessura da parede $(\mu \mathrm{m})$ & 1,46 & 2,56 & 3,67 \\
\hline Fração parede (\%) & 18,18 & 28,57 & 36,92 \\
\hline Comprimento $(\mu \mathrm{m})$ & $744 \pm 328$ & $1028 \pm 367$ & $1056 \pm 388$ \\
\hline Largura $(\mu \mathrm{m})$ & $18 \pm 2,7$ & $24 \pm 3$ & $25 \pm 3,4$ \\
\hline Área ocupada (\%) & 52 & 62 & 63 \\
\hline Coef. rigidez (\%) & 18,82 & 71,43 & 63,08 \\
\hline Coef. Flexibilidade & 50 & 41,66 & 80 \\
\hline Índice de Runkel & 0,20 & 0,40 & 0,58 \\
\hline Grupos de Runkel & I & II & III \\
\hline Parênquima axial (\%) & 20 & 18 & 19 \\
\hline Densidade básica $\left(\mathrm{kg} / \mathrm{m}^{3}\right)$ & 480 & 650 & 670 \\
\hline Densidade seca $\left(\mathrm{kg} / \mathrm{m}^{3}\right)$ & 486 & 657 & 676 \\
\hline
\end{tabular}




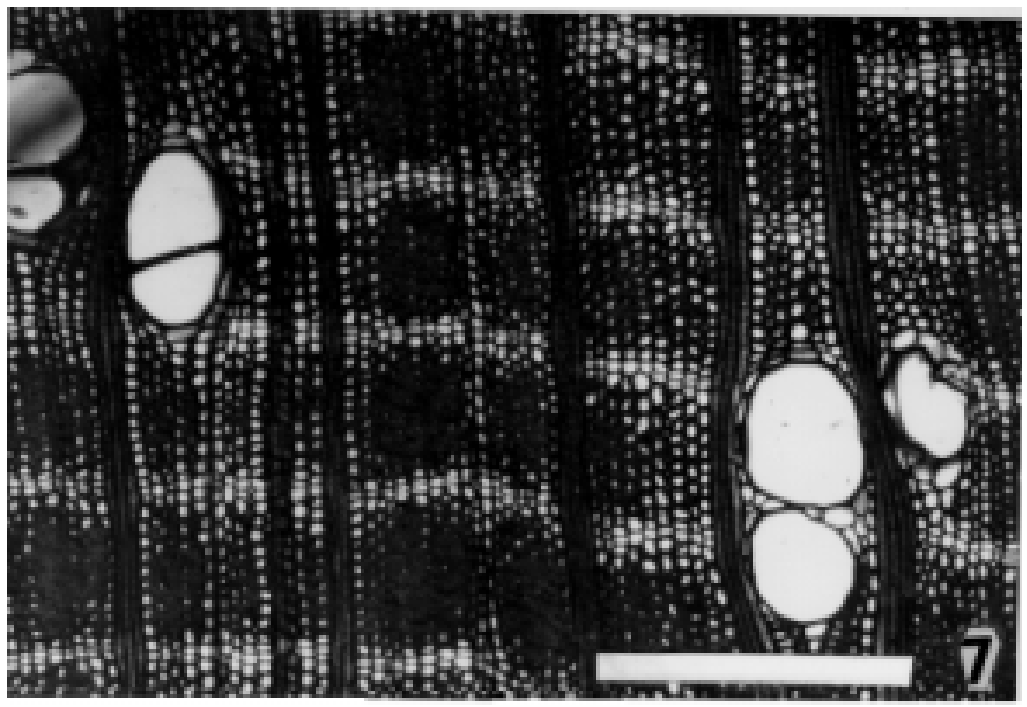

Figura 7 - Duguetia cauliflora: corte transversal mostrando abundância de fibras e pouco parênquima axial apotraqueal (partes claras entre os raios); escala de $200 \mu \mathrm{m}$.

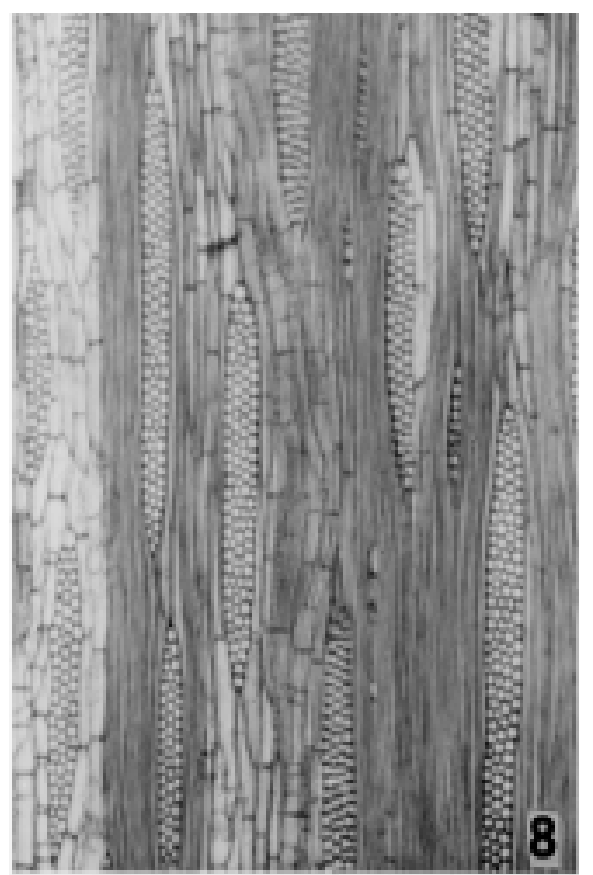

Figura 8 - Duguetia cauliflora: corte tangencial mostrando raios multiseriados e fibras (partes estriadas); escala de $200 \mu \mathrm{m}$.
4. Eschweilera matamata (tabela 4; figuras 9 e 10). Vasos- De distribuição difusa, solitários, geminados e múltiplos radiais de até 5 elementos e múltiplos em cachos de até 6 elementos (figuras 9 e 10), sem predominância de nenhum dos tipos nas 4 áreas, a média do diâmetro tangencial das 4 áreas foi de $256 \mu \mathrm{m}$; na área 1, a variação foi de $248 \mu \mathrm{m}$ a $279 \mu \mathrm{m}$, na área 2, de 197 a $218 \mu \mathrm{m}$, na área 3 a variação foi de 332 a $361 \mu \mathrm{m}$ e na área 4 variou entre 191 e $221 \mu \mathrm{m}$. Elementos de vaso- com placa de perfuração simples, terminal e total, apêndice numa ou nas duas extremidades, cujo comprimento médio na área 1 foi de $493 \mu \mathrm{m}$, variando entre 410 e $560 \mu \mathrm{m}$, na área 2 a média foi de $417 \mu \mathrm{m}$, variando de 310 a $620 \mu \mathrm{m}$, na área 3 a média foi de $550 \mu \mathrm{m}$, com variação entre 420 e $700 \mu \mathrm{m}$ e na área 4 a média foi de $532 \mu \mathrm{m}$, variando de 484 a $636 \mu \mathrm{m}$, enquanto que a largura média foi de 277, 218, 366 e 217 $\mu \mathrm{m}$, respectivamente nas áreas $1,2,3$ e 4. Pontuações intervasculares alternas, areoladas, com abertura inclusa e circular. Parênquima axial - nas 4 áreas é apotraqueal, subagregado representado por faixas curtas tangenciais, de 1-2 camadas de células de largura, dispostas entre os raios. Nas áreas 1 e 2 a fração parede das células desse parênquima foi de $18 \%$ e nas 
áreas 3 e 4 foi de $22 \%$. Raios- homogêneos, constituídos de células procumbentes; nas áreas 1,2 e 3 predominam os 2-seriados, ocorrendo também 3-seriados, enquanto que na área 4 predominam os 3-seriados. Os dados referentes à largura e à altura constam da tabela 4 . A fração parede das células radiais foi de $16 \%$,
$18 \%, 24 \%$ e $26 \%$, respectivamente para as áreas 1, 2, 3 e 4. Fibras- Moderadamente abundantes, de parede fina em relação ao espaço ocupado por cada fibra; na área 1 a variação do comprimento foi de 1428 a $1482 \mu \mathrm{m}$, na área 2 entre 1420 e $1453 \mu \mathrm{m}$, na área 3 de 1698 e 1720 $\mu \mathrm{m}$ e na área 4 foi de 1580 a $1660 \mu \mathrm{m}$.

Tabela 4 - Eschweilera matamata - densidade e parâmetros anatômicos quantitativos dos elementos constituintes da madeira para análise de qualidade

\begin{tabular}{|c|c|c|c|c|}
\hline Parâmetros mensurados & Área 1 & Área 2 & Área 3 & Área 4 \\
\hline \multicolumn{5}{|l|}{ Vasos } \\
\hline Diâmetro ( $\mu \mathrm{m})$ & $265 \pm 4,6$ & $208 \pm 3,58$ & $347 \pm 7,9$ & $203 \pm 2$ \\
\hline Quantidade (/mm2) & $1,8 \pm 0,78$ & $1,5 \pm 0,72$ & $1,9 \pm 0,73$ & $2,4 \pm 0,61$ \\
\hline Fração parede & 4,7 & 5,2 & 4,3 & \\
\hline Área ocupada (\%) & 9,6 & 9 & 8,5 & 9 \\
\hline \multicolumn{5}{|l|}{ Raios } \\
\hline \multicolumn{5}{|l|}{ Altura $(\mu \mathrm{m})$} \\
\hline 2-seriados & $554 \pm 141$ & $367 \pm 99,2$ & $443 \pm 196$ & $401 \pm 165$ \\
\hline 3-seriados & $716 \pm 178$ & $689 \pm 163$ & $533 \pm 143$ & $618 \pm 127,2$ \\
\hline \multicolumn{5}{|l|}{ Largura $(\mu \mathrm{m})$} \\
\hline 2-seriados & $31 \pm 11,9$ & $30 \pm 6,4$ & $34 \pm 5,1$ & $37 \pm 4,9$ \\
\hline 3-seriados & $50,2 \pm 9,1$ & $9,1 \pm 3,5$ & $50 \pm 6$ & $45 \pm 8,1$ \\
\hline \multicolumn{5}{|l|}{ Quantidade (/mm) } \\
\hline 2-seriados & $1,9 \pm 0,99$ & $2,8 \pm 1,47$ & $1,8 \pm 0,78$ & $1,5 \pm 0,52$ \\
\hline 3-seriados & $3,1 \pm 1,2$ & $6,1 \pm 1,10$ & $3,6 \pm 0,51$ & $4,2 \pm 0,63$ \\
\hline Área ocupada (\%) & 26,5 & 27,3 & 25,8 & 25,5 \\
\hline \multicolumn{5}{|l|}{ Fibras } \\
\hline Diâmetro $(\mu \mathrm{m})$ & 18 & 18 & 16 & 18 \\
\hline Comprimento $(\mu \mathrm{m})$ & $1460 \pm 330$ & $1435 \pm 413$ & $1705 \pm 177,6$ & $1600 \pm 335$ \\
\hline Esp. Parede $(\mu \mathrm{m})$ & 2,3 & 3 & 3,4 & 4,8 \\
\hline Largura $(\mu \mathrm{m})$ & $17 \pm 4,8$ & $19 \pm 3$ & $18 \pm 4,2$ & $15 \pm 5$ \\
\hline Fração parede (\%) & 25,5 & 33,3 & 43 & 51 \\
\hline Coef. Flexibilidade & 86 & 33,3 & 43 & 51 \\
\hline Coef. rigidez (\%) & 74,4 & 66,6 & 56 & 49 \\
\hline Índice de Runkel & 0,25 & 0,33 & 0,43 & 0,51 \\
\hline Grupo de Runkel & 1 & $\|$ & $\|$ & ॥ \\
\hline Diâmetro $(\mu \mathrm{m})$ & 13,4 & 12 & 9 & 8,8 \\
\hline Área ocupada (\%) & 49,9 & 48,2 & 50,1 & 52,3 \\
\hline Parênquima axial (\%) & 13 & 13,5 & 14,2 & 13,4 \\
\hline Densidade seca $\left(\mathrm{kg} / \mathrm{m}^{3}\right)$ & 530 & 550 & 610 & 660 \\
\hline Densidade básica $\left(\mathrm{kg} / \mathrm{m}^{3}\right)$ & 480 & 510 & 560 & 610 \\
\hline
\end{tabular}




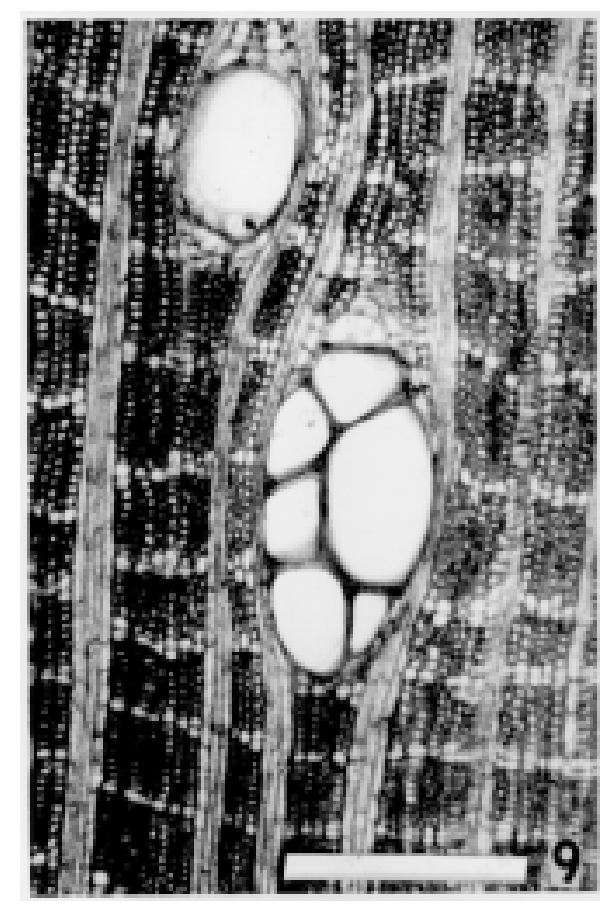

Figura 9 - Eschweilera matamata: corte transversal mostrando vaso múltiplo em cacho e parênquima axial apotraqueal (partes claras estreitas); escala de $200 \mu \mathrm{m}$.

5. Myrocarpus frondosus (tabela 5; figuras 11 e 12). Vasos - de distribuição difusa, sendo que os solitários são os predominantes, ocorrendo também geminados, cujo diâmetro tangencial variou na área 1 de 143 a 168 $\mu \mathrm{m}$, na área 2 de 148 a $172 \mu \mathrm{m}$ e na área 3 entre 152 e $192 \mu \mathrm{m}$ e a ocorrência por $\mathrm{mm}^{2}$ foi de 2 a 5 na área 1 , na área 2 foi de 1 a 3,5 e na área 3 de 0,7 a 1,8. Elementos de vasocom placa de perfuração simples, total e terminal, com apêndices nas duas extremidades, cujo comprimento médio das 3 áreas foi de $380 \mu \mathrm{m}$, variando entre 310 e 430 $\mu \mathrm{m}$ na área 1 , de 318 a $443 \mu \mathrm{m}$ na área $2 \mathrm{e}$ de 338 a $463 \mu \mathrm{m}$ na área 3 , sendo que a largura média das 3 áreas foi da ordem de $263 \mu \mathrm{m}$, variando de 120 a $300 \mu \mathrm{m}$ na área 1,131 a $312 \mu \mathrm{m}$ na área 2 e entre 142 e $334 \mu \mathrm{m}$ na área 3. Pontuações intervasculares areoladas, alternas, com abertura inclusa. Parênquima

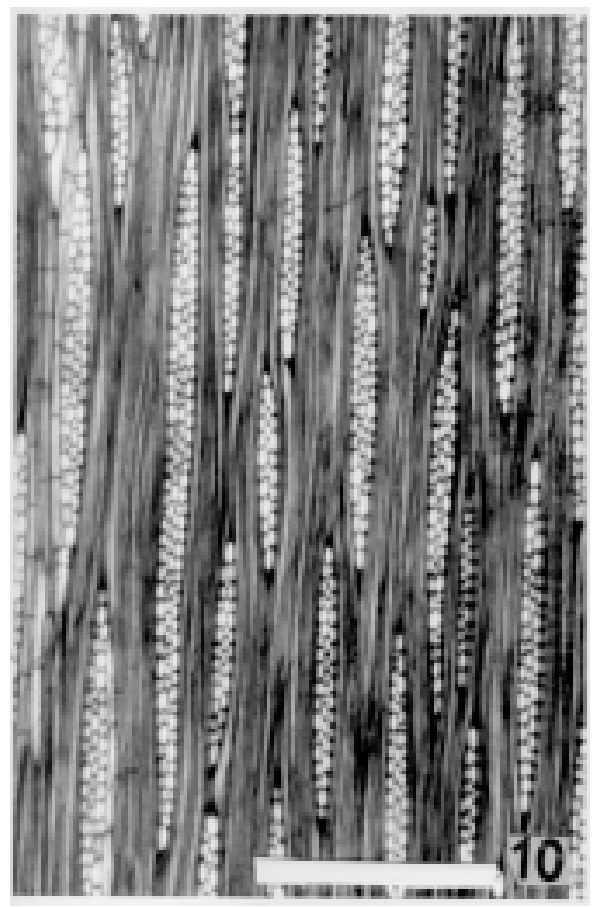

Figura 10 - Eschweilera matamata: corte tangencial mostrando predominância de raios 2-seriados; escala de $200 \mu \mathrm{m}$.

axial, pouco, paratraqueal, confluente, as vezes alado; a fração parede das células parenquimatosas foi de 8,84, 16 e 15,33\%, respectivamente para as áreas 1,2 e 3 . Raios- homogêneos, constituídos de células procumbentes (horizontais) vistos em cortes radiais, 2 a 3-seriados. Na área 1 a altura variou entre 191 e $837 \mu \mathrm{m}$, na área 2 de 851 a $933 \mu \mathrm{m}$ e na área 3 entre 922 e $959 \mu \mathrm{m}$; a largura na área 1 variou de 43 a $62 \mu \mathrm{m}$, na área 2 de 44 a $64 \mu \mathrm{m}$ e na área 3 entre $42 \mathrm{e}$ $2 \mu \mathrm{m}$; a fração parede das células desse parênquima foi de $12,7 \%, 18 \%$ e $19,7 \%$, respectivamente para áreas 1,2 e 3 . Fibras- abundantes nas 3 áreas, de parede fina em relação a área ocupada por cada fibra, curtas na área 1, variando entre $1218 \mathrm{e}$ $1387 \mu \mathrm{m}$, e longas nas áreas 2 e 3, entre 1525 e 1618 e de 1528 a $178 \mu \mathrm{m}$, respectivamente. 
Tabela 5 - Mirocarpus frondosus - densidade e parâmetros anatômicos dos elementos constituintes da madeira para análise de qualidade

\begin{tabular}{|c|c|c|c|}
\hline Parâmetros mensurados & Área I & Área 2 & Área 3 \\
\hline \multicolumn{4}{|l|}{ Vasos } \\
\hline Diâmetro $(\mu \mathrm{m})$ & $|5| \pm 21,21$ & $154 \pm 33,70$ & $173 \pm 21,96$ \\
\hline Quantidade (/mm2) & $3,41 \pm 1,44$ & $2,92 \pm 1,38$ & $4,4 \pm 1,4$ \\
\hline Fração parede (\%) & 9,55 & 8,82 & 9,37 \\
\hline \multicolumn{4}{|l|}{ Raios } \\
\hline Altura $(\mu \mathrm{m})$ & $8 \| \pm 274,9$ & $896 \pm 282,96$ & $949 \pm 281,28$ \\
\hline Largura $(\mu \mathrm{m})$ & $56 \pm \| 1,2 \mid$ & $51 \pm 7,57$ & $54 \pm 8,34$ \\
\hline Quantidade (/mm) & $3,78 \pm 0,89$ & $4,26 \pm 0,79$ & $4,2 \pm 0,77$ \\
\hline Área ocupada (\%) & 21,81 & 25,71 & 15 \\
\hline \multicolumn{4}{|l|}{ Fibras } \\
\hline Diâmetro $(\mu \mathrm{m})$ & 13,18 & 13,80 & 16,10 \\
\hline Comprimento $(\mu \mathrm{m})$ & $1336 \pm 178,2$ & $1550 \pm 199,95$ & $1566 \pm 207,27$ \\
\hline Espessura da parede $(\mu \mathrm{m})$ & 2,99 & 4 & 5,90 \\
\hline Área ocupada (\%) & 51,33 & 48,59 & 69,27 \\
\hline Largura $(\mu \mathrm{m})$ & $20 \pm 4,77$ & $20,93 \pm 3,63$ & $21,63 \pm 6,3$ \\
\hline Fração parede (\%) & 43,33 & 57,97 & 65,71 \\
\hline Coef. flexibilidade(\%) & $66,60 \pm 37,59$ & $74 \pm 55$ & $72,39 \pm 31,26$ \\
\hline Coef. de rigidez (\%) & 56,67 & 42,03 & 34,29 \\
\hline Índice de Runkel & 0,42 & 0,42 & 1,92 \\
\hline Grupo de Runkel & ॥ & ॥ & IV \\
\hline Área ocupada (\%) & 41,39 & 56,82 & 69,27 \\
\hline Diâmetro do lume $(\mu \mathrm{m})$ & 7,2 & 9,66 & 5,51 \\
\hline Parênquima axial (\%) & 16 & 15 & 14,3 \\
\hline Densidade seca $\left(\mathrm{kg} / \mathrm{m}^{3}\right)$ & 800 & 810 & 830 \\
\hline Densidade básica $\left(\mathrm{kg} / \mathrm{m}^{3}\right)$ & 730 & 760 & 810 \\
\hline
\end{tabular}

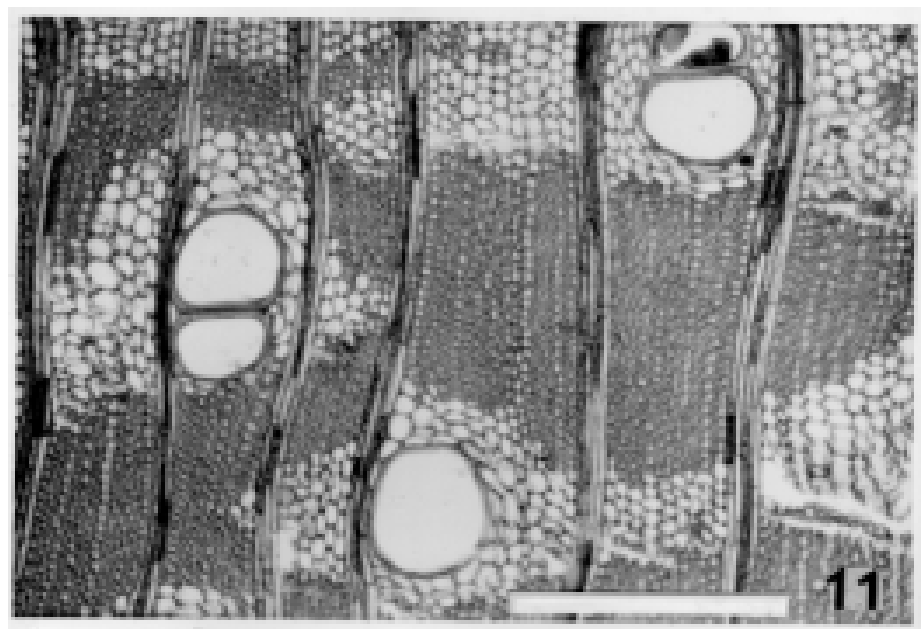

Figura 11 - Myrocarpus frondosus: corte transversal mostrando parênquima axial paratraqueal em faixas e vasicêntrico com tendência a alado e abundância de fibras (partes escuras); escala de $200 \mu \mathrm{m}$. 


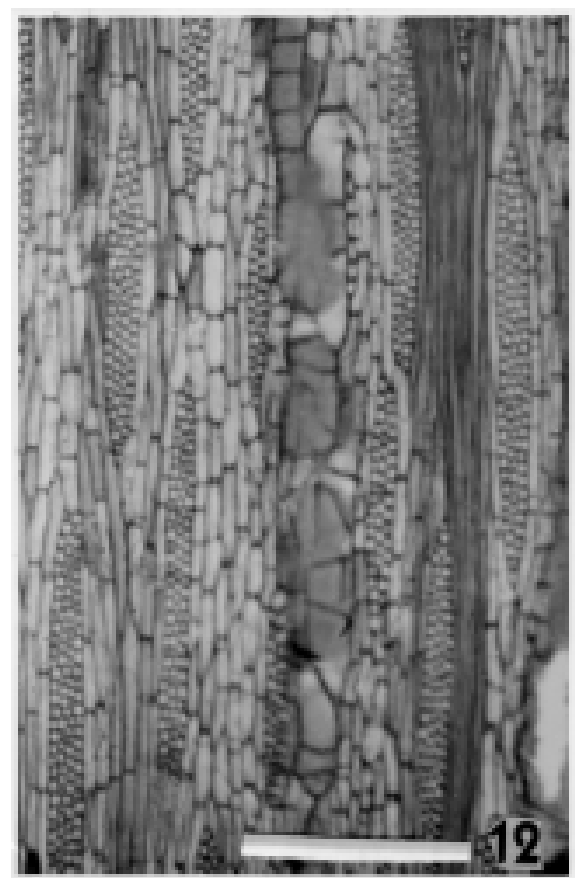

Figura 12 - Myrocarpus frondosus: corte radial mostrando células procumbentes; escala de de $200 \mu \mathrm{m}$.

\section{Parkia multijuga (tabela 6; figuras 13}

e 14). Vasos- distribuição difusa, predominantemente solitários nas 4 áreas, diâmetro tangencial variou entre 195 e $215 \mu \mathrm{m}$ na área 1 , na área 2 de 214 a $236 \mu \mathrm{m}$, na área 3 entre 238 e $256 \mu \mathrm{m}$ e na área 4 de 242 a 266 $\mu \mathrm{m}$, ocorrendo também geminados, as vezes múltiplos em cachos ou radiais de até 4 elementos. Elementos de vaso- com placa de perfuração simples, total e terminal, as vezes pode ocorrer apêndice em uma das extremidades nas 4 áreas. Pontuações intervasculares alternas, areoladas, guarnecidas, com abertura inclusa nas 4 áreas, na área 1 o comprimento médio desses elementos foi de $375 \mu \mathrm{m}$, variando entre 351 e $389 \mu \mathrm{m}$, na área 2 a média foi de $450 \mathrm{~mm}$, variando de 438 a 560 $\mu \mathrm{m}$, na área 3 foi de $462 \mu \mathrm{m}$, variando entre 449 e $477 \mu \mathrm{m}$, e na área 4 de $520 \mu \mathrm{m}$, variando entre 509 e $539 \mu \mathrm{m}$, enquanto que a largura média na área 1 foi de $227 \mu \mathrm{m}$, variando de 210 a $238 \mu \mathrm{m}$, na área 2 foi de $242 \mu \mathrm{m}$, variando entre 227 e $249 \mu \mathrm{m}$, área 3 foi de $260 \mu \mathrm{m}$, variando entre 254 e $287 \mu \mathrm{m}$ e na área $4 \mathrm{a}$ média foi de $362 \mu \mathrm{m}$, variando entre 332 e 383 $\mu \mathrm{m}$. Raios, homogêneos, constituídos exclusivamente de células quadradas nas 4 áreas. Em todas as áreas ocorrem raios com cristais rômbicos de oxalato de cálcio; a fração parede das células radiais foi de $12,6 \%, 13 \%, 15 \%$ e $17 \%$, respectivamente para área 1 , área 2 , área 3 e área 4. Parênquima axial- pouco, paratraqueal, vasicêntrico nas 4 áreas. Camadas de crescimento evidentes na área 1; a fração parede das células desse parênquima foi de $8 \%$, $10,6 \%, 12 \%$ e $14 \%$, respectivamente para áreas 1, 2, 3 e 4. Fibras- abundantes nas 4 áreas, de parede fina em relação ao espaço ocupado por cada fibra, curtas na área 1, variando de 1.100 a $1.700 \mu \mathrm{m}$, longas na área 2, variando de $1.200 \mathrm{a}$ $1.800 \mu \mathrm{m}$, longas na área 3, variando de 1.260 a $1.900 \mu \mathrm{m}$ e na área 4 igualmente longas, variando entre 1.300 e $2.600 \mu \mathrm{m}$.

7. Sloanea grandis (tabela 7; figuras 15 , 16 e 17). Vasos- Distribuição difusa, geminados e múltiplos radiais de até 3 elementos nas 4 áreas; foram observados na área 4, vasos múltiplos de até 4 elementos, ocorreram também solitários na área 1 . São freqüentes vasos com tilos esclerosados e celulósicos nas áreas 1,2 e 3 , as vezes, formando redes dentro do lume; diâmetro tangencial de tamanho médio nas 4 áreas amostradas. Na área 1 o diâmetro variou de 85 a $167 \mu \mathrm{m}$, na área 2 a variação foi de entre 73 e $156 \mu \mathrm{m}$, na área 3 de 89 a 161 $\mu \mathrm{m}$ e na área 4 entre 80 e $113 \mu \mathrm{m}$; poucos nas 4 áreas estudadas, sendo que nas áreas 1 e 2 variaram de 2 a 6 por $\mathrm{mm}^{2}$; na área 3 entre $1 \mathrm{e}$ 5 vasos por $\mathrm{mm}^{2}$ e na área 4 de 2 a 4 vasos por $\mathrm{mm}^{2}$. Elementos de vaso- com apêndice curto, as vezes nas duas extremidades, placa de perfuração simples, total e terminal. Pontuações intervasculares areoladas, opostas, com abertura exclusa e também exclusa coalescente nas 4 áreas. Quanto ao comprimento, são considerados muito longos nas 4 áreas, na área 1 a média foi de $776 \mu \mathrm{m}$, variando de 664 a $1040 \mu \mathrm{m}$, na área 2 foi de $914 \mu \mathrm{m}$, variando entre 700 e $1050 \mu \mathrm{m}$, na área 3 foi de $878 \mu \mathrm{m}$, variando de 620 a $1170 \mu \mathrm{m}$, e na área 4 a média foi de $681 \mu \mathrm{m}$, variando entre 370 a $1000 \mu \mathrm{m}$; a largura media na área 1 foi de $136 \mu \mathrm{m}$, variando entre 123 e $147 \mu \mathrm{m}$, 
Tabela 6 - Parkia multijuga- densidade e parâmetros anatômicos quantitativos dos elementos constituintes da madeira para análise de qualidade

\begin{tabular}{|c|c|c|c|c|}
\hline Parâmetros mensurados & Área 1 & Área 2 & Área 3 & Área 4 \\
\hline \multicolumn{5}{|l|}{ Vasos } \\
\hline Diâmetro $(\mu \mathrm{m})$ & $207 \pm 37,8$ & $226 \pm 41,6$ & $245,6 \pm 51,1$ & $253 \pm 37,2$ \\
\hline Área ocupada (\%) & 5,95 & 12,95 & 12,52 & 3,74 \\
\hline \multicolumn{5}{|l|}{ Quantidade (/mm2) } \\
\hline Solitários & 19 & 17,7 & 18 & 16 \\
\hline Geminados & 1,47 & 3,12 & 1,3 & 3,7 \\
\hline Múltiplos & 4,4 & 4,15 & 5,5 & 5 \\
\hline Fração parede (\%) & 8,6 & 4,87 & 7,6 & 4,73 \\
\hline \multicolumn{5}{|l|}{ Raios } \\
\hline \multicolumn{5}{|l|}{ Altura $(\mu \mathrm{m})$} \\
\hline I-seriados & $304 \pm 96,5$ & $190 \pm 81,5$ & $207 \pm 95,1$ & $152 \pm 65$ \\
\hline 2-seriados & $420 \pm 92,2$ & $257 \pm 91,2$ & $286 \pm 156$ & $197 \pm 144,4$ \\
\hline 3-seriados & $406 \pm 95,8$ & $392 \pm 106$ & $406 \pm 105$ & $335 \pm 144,4$ \\
\hline 4-seriados & $508 \pm 118,4$ & $553 \pm|3|, 8$ & $566 \pm 108$ & $515 \pm 158$ \\
\hline \multicolumn{5}{|l|}{ Quantidade (/mm) } \\
\hline I-seriados & $304 \pm 96,5$ & $190 \pm 81,5$ & $207 \pm 95, I$ & $152 \pm 65$ \\
\hline 2-seriados & $420 \pm 92,2$ & $257 \pm 91,2$ & $286 \pm 156$ & $197 \pm 144,4$ \\
\hline 3-seriados & $406 \pm 95,8$ & $257 \pm 91,2$ & $406 \pm 105$ & $335 \pm 144,4$ \\
\hline 4-seriados & $508 \pm 118,4$ & $553 \pm 11,8$ & $566 \pm 108$ & $515 \pm 158$ \\
\hline \multicolumn{5}{|l|}{ Largura $(\mu \mathrm{m})$} \\
\hline I-seriados & $10 \pm 0$ & $10 \pm 0$ & $10 \pm 0$ & $11 \pm 2,7$ \\
\hline 2-seriados & $19 \pm 2,7$ & $18 \pm 5$ & $17,6 \pm 4,3$ & $19,6 \pm 5,3$ \\
\hline 3-seriados & $24,4 \pm 7,1$ & $26,4 \pm 4,8$ & $23,6 \pm 4,8$ & $26,8 \pm 6,2$ \\
\hline 4 -seriados & $35 \pm 7,7$ & $33 \pm 6, I$ & $34 \pm 6,5$ & $35,6 \pm 5,8$ \\
\hline \multicolumn{5}{|l|}{ Área ocupada (\%) } \\
\hline I-seriados & 1,44 & 0,32 & 0,16 & 0,12 \\
\hline 2-seriados & 1,4 & 0,72 & 0,48 & 0,28 \\
\hline 3-seriados & 0,32 & 0,52 & 0,72 & 1,12 \\
\hline 4-seriados & 0,08 & 0,72 & 0,56 & 1,32 \\
\hline \multicolumn{5}{|l|}{ Fibras } \\
\hline Diâmetro $(\mu \mathrm{m})$ & 32 & 27,6 & 25,3 & 23 \\
\hline Área ocupada (\%) & 75,44 & 61,28 & 60,41 & 74,35 \\
\hline Comprimento $(\mu \mathrm{m})$ & $1442 \pm 195,6$ & $1546 \pm 21,50$ & $1580 \pm 247$ & $1758 \pm 354 / 3$ \\
\hline Espessura da parede $(\mu \mathrm{m})$ & 2,3 & 5,29 & 6,21 & 7,36 \\
\hline Largura $(\mu \mathrm{m})$ & $34 \pm 0,65$ & $29 \pm 0,65$ & $28 \pm 0,59$ & $25 \pm 0,58$ \\
\hline Fração parede (\%) & 14,37 & 38,3 & 54 & 64 \\
\hline Coef. Flexibilidade & 42 & 53 & 56 & 70 \\
\hline Coef. rigidez (\%) & 85,63 & 61,7 & 46 & 36 \\
\hline Índice de Runkel & 0,19 & 0,62 & 1,0 & 1,77 \\
\hline Grupo de Runkel & 1 & III & III & IV \\
\hline Parênquima axial (\%) & 5,5 & 12,45 & 12,52 & 10,06 \\
\hline Densidade seca $\left(\mathrm{kg} / \mathrm{m}^{3}\right)$ & 266 & 381 & 429 & 534 \\
\hline Densidade básica $\left(\mathrm{kg} / \mathrm{m}^{3}\right)$ & 219 & 320 & 379 & 449 \\
\hline
\end{tabular}




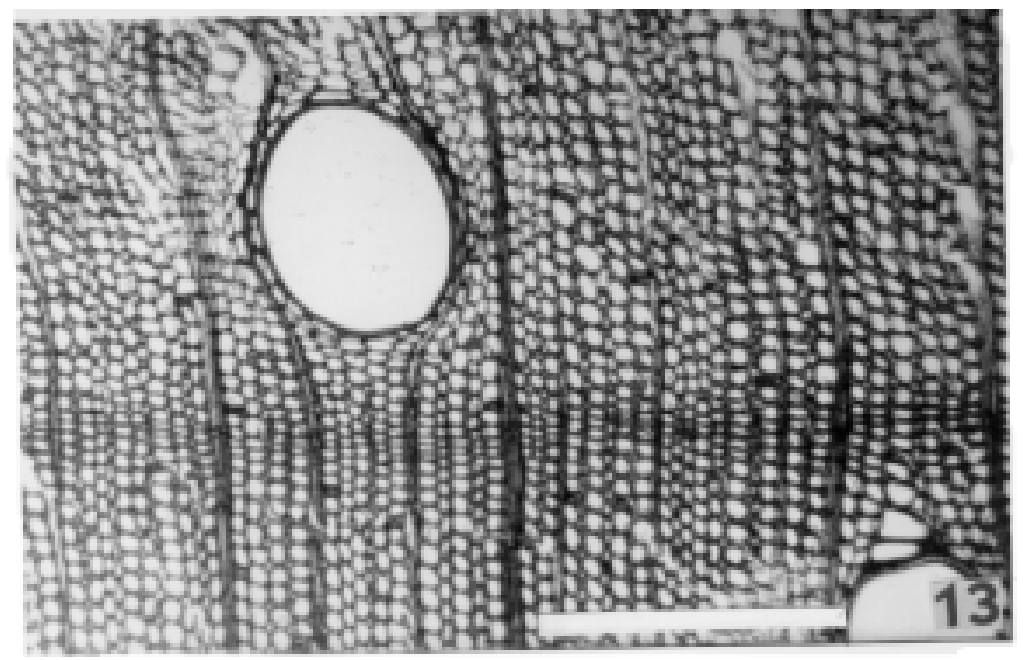

Figura 13 - Parkia multijuga: corte transversal evidenciando fibras abundantes de parede fina e uma camada de crescimento; escala de $200 \mu \mathrm{m}$.

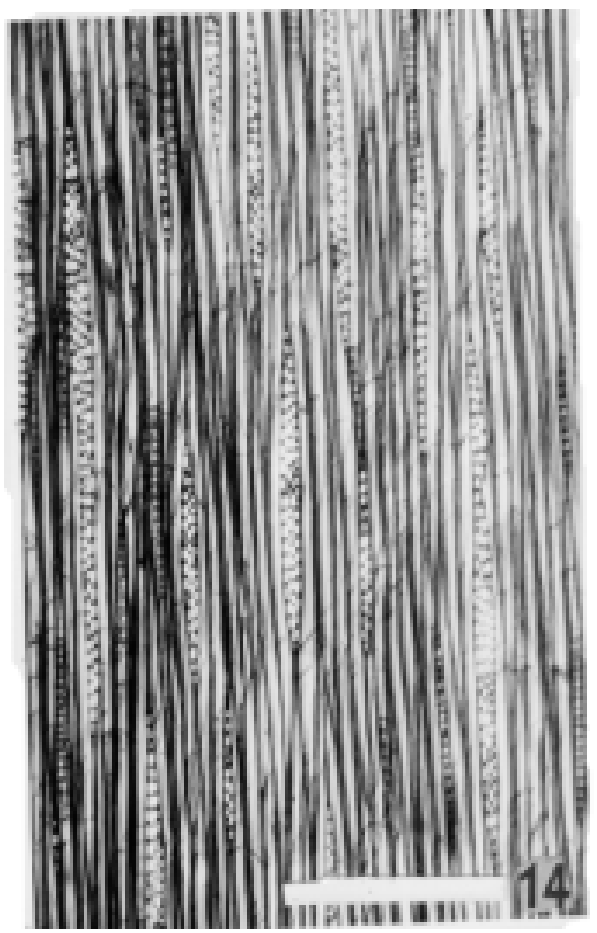

Figura 14 - Parkia multijuga: corte tangencial mostrando predominância de raios 2-seriados; escala de $200 \mu \mathrm{m}$. na área 2 foi de $128 \mu \mathrm{m}$, variando de 111 a 141 $\mu \mathrm{m}$, na área 3 a média foi da ordem de $133 \mu \mathrm{m}$, variando entre 120 e $143 \mu \mathrm{m}$ e na área 4 foi de $121 \mu \mathrm{m}$, variando de 112 a $140 \mu \mathrm{m}$. Parênquima axial- de escasso a pouco, as vezes quase ausente, apotraqueal nas áreas 1 e 2, paratraqueal nas áreas 3 e 4; a fração parede das células desse parênquima foi de $25 \%, 28 \%$, $25,5 \%$ e $28 \%$, respectivamente para as áreas 1, 2, 3 e 4. Raios- nas 4 áreas são homogêneos, constituídos de células quadradas; na área 4 ocorrem também homogêneos constituídos de células procumbentes; na área 1 predominam os uniseriados, na área 2 são de 2 a 9-seriados, na área 3 de 5 a 9-seriados e na área 4 entre 7 e 10-seriados, ocorrendo também 2-seriados; pouco numerosos nas áreas 1 e 2, variando de 5 a 9 raios por $\mathrm{mm}$, e de 7 a 9 por $\mathrm{mm}$ nas áreas 3 e 4, e são considerados também pouco numerosos. Com relação a largura, os raios são considerados finos nas áreas 1 e 2 , os quais variam de 25 a $46 \mu \mathrm{m}$ na área 1 , de 28 a $37 \mu \mathrm{m}$ na área 2, nas demais áreas são estreitos, sendo que na área 3 a variação foi de 18 a $29 \mu \mathrm{m}$ e na área 4 entre 52 e $69 \mu \mathrm{m}$. Quanto às alturas são baixas nas 4 áreas e variam de 550 a 2040 $\mu \mathrm{m}$ na área 1 , entre 800 e $1950 \mu \mathrm{m}$ na área 2 , de 610 a $1900 \mu \mathrm{m}$ na área 3 e de 800 a 1800 $\mu \mathrm{m}$ na área 4. São freqüentes células radiais 
com cristais de oxalato de cálcio, de forma rômbica, nas 4 áreas estudadas; a fração parede das células radiais foi de $26 \%, 26,5 \%, 29 \%$ e $29,6 \%$, respectivamente para as áreas $1,2,3$ e 4. Fibra, abundantes de parede espessa na área 1 e muito espessa nas áreas 2, 3 e 4; são longas nas 4 áreas, cujo comprimento variou de 910 a $2300 \mu \mathrm{m}$ na área 1 , entre 980 e $2300 \mu \mathrm{m}$ na área 2 , de 1300 a $1850 \mu \mathrm{m}$ na área 3 e entre 1050 e $2100 \mu \mathrm{m}$ na área 4.
O lenho juvenil, em todas as espécies estudadas, apresentou fibras de parede bem mais fina, quando comparada com as fibras das áreas 2, 3 e 4, que têm fibras de parede mais espessa, refletindo na elevação da densidade (Fig. 1). Além disso, no lenho juvenil, o número de vasos por $\mathrm{mm}^{2}$ foi sempre maior em relação ao das outras áreas, exceto em Eschweilera matamata que apresentou 2,4 vasos por $\mathrm{mm}^{2}$ na área 4 e 1,8 por $\mathrm{mm}^{2}$ na área 1.

Tabela 7 - Sloanea grandis - densidade e parâmetros anatômicos quantitativos dos elementos constituintes da madeira para análise de qualidade.

\begin{tabular}{|c|c|c|c|c|}
\hline Parâmetros mensurados & Área I & Área 2 & Área 3 & Área 4 \\
\hline \multicolumn{5}{|l|}{ Vasos } \\
\hline Diâmetro $(/ \mu \mathrm{m})$ & $|3| \pm 21,45$ & $119 \pm 21,34$ & $124 \pm 18,4$ & $104 \pm 18,65$ \\
\hline Quantidade (/mm2) & $3,56 \pm 1,16$ & $3,56 \pm 1,34$ & $3 \pm 1,10$ & $4,36 \pm 1,25$ \\
\hline Fração parede (\%) & 6,45 & 6,56 & 8,89 & 7,2 \\
\hline Área ocupada (\%) & 9,3 & 9,2 & 9 & 7,6 \\
\hline \multicolumn{5}{|l|}{ Raios } \\
\hline Altura média dos raios $(\mu \mathrm{m})$ & $\mid 205 \pm 376,71$ & $1275 \pm 2588,88$ & $1100 \pm 324,8$ & $1080 \pm 230,7$ \\
\hline Largura média dos raios $(\mu \mathrm{m})$ & $32,75 \pm 22,82$ & $34,0 \pm 23,44$ & $57 \pm 23,75$ & $58,79 \pm 28,12$ \\
\hline Quantidade média (/mm) & $8,6 \pm 1,27$ & $7,8 \pm 0,79$ & $6 \pm 0,82$ & $5,6 \pm 1,02$ \\
\hline I-seriados & 6,63 & 6,8 & 6,5 & 5,71 \\
\hline 2-seriados & 6,98 & 1,66 & & 5,36 \\
\hline 3-seriados & 2,33 & & & \\
\hline 4-seriados & 4,65 & 5,13 & & \\
\hline 5 -seriados & 4,65 & 6,41 & & \\
\hline 6 -seriados & 4,65 & 6,41 & 1,66 & \\
\hline 7 -seriados & 4,65 & 12,82 & 3,33 & 17,86 \\
\hline 8 -seriados & 6,98 & 12,82 & 8,33 & 17,86 \\
\hline 9-seriados & 3,49 & 5,13 & 8,33 & 3,21 \\
\hline 10 -seriados & & & 8,33 & 3,57 \\
\hline \multicolumn{5}{|l|}{ Fibras } \\
\hline Diâmetro $(\mu \mathrm{m})$ & 10 & 7,5 & 6,5 & 6 \\
\hline Comprimento $(\mu \mathrm{m})$ & $1638 \pm 438,66$ & $1818 \pm 408$ & $1527 \pm|8|, 7$ & $1533 \pm 306$ \\
\hline Espessura da parede $(\mu \mathrm{m})$ & 2,6 & 2,7 & 2,5 & 2,5 \\
\hline Largura $(\mu \mathrm{m})$ & $26 \pm 3,08$ & $23,69 \pm 3,08$ & $24 \pm 2,47$ & $24 \pm 2,95$ \\
\hline Fração parede (\%) & 54 & 72 & 76,92 & 83,33 \\
\hline Coef. flexibilidade & 92 & 76,74 & 63,86 & 64,10 \\
\hline Coef. rigidez (\%) & 30,67 & 46 & 23 & 16,67 \\
\hline Índice de Runkel & 1,17 & 2,26 & 3,33 & 5,0 \\
\hline Área ocupada (\%) & 69,49 & 74,13 & 72,80 & 71,60 \\
\hline Grupo de Runkel & IV & V & V & V \\
\hline Parênquima axial (\%) & 5,21 & 6,67 & 8,3 & 12,8 \\
\hline Densidade seca $(\mathrm{kg} / \mathrm{m} 3)$ & 695 & 857 & 950 & 1194 \\
\hline Densidade básica $(\mathrm{kg} / \mathrm{m} 3)$ & 619 & 807 & 943 & 1187 \\
\hline
\end{tabular}




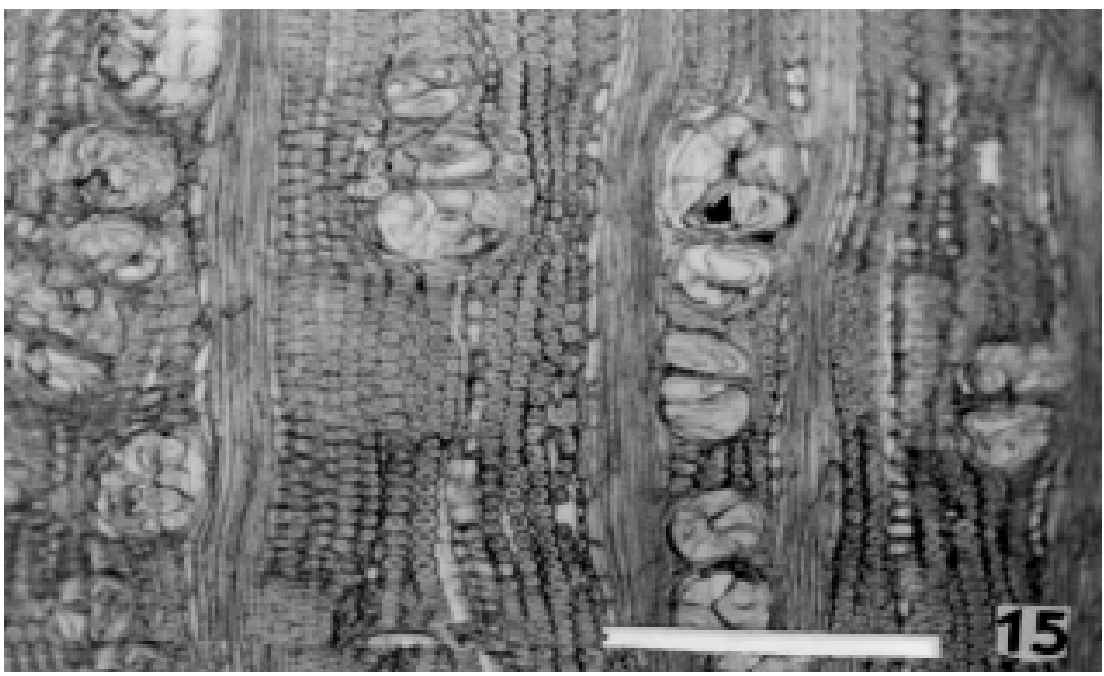

Figura 15 - Sloanea grandis: corte transversal mostrando escassez de parênquima axial paratraqueal e abundância de fibras de parede espessa; escala de $200 \mu \mathrm{m}$.

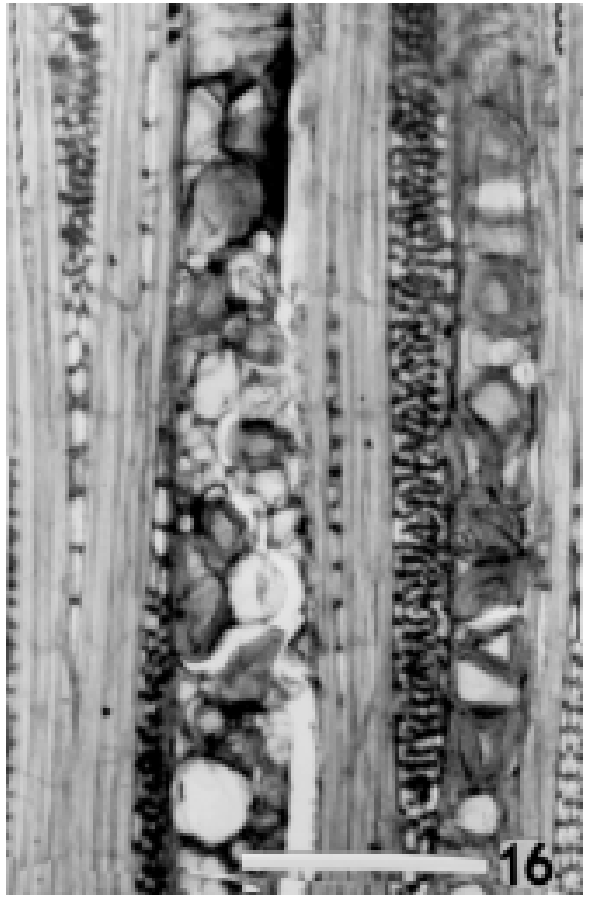

Figura 16 - Sloanea grandis: corte radial mostrando tilos esclerosados nos vasos; escala de $200 \mu \mathrm{m}$.

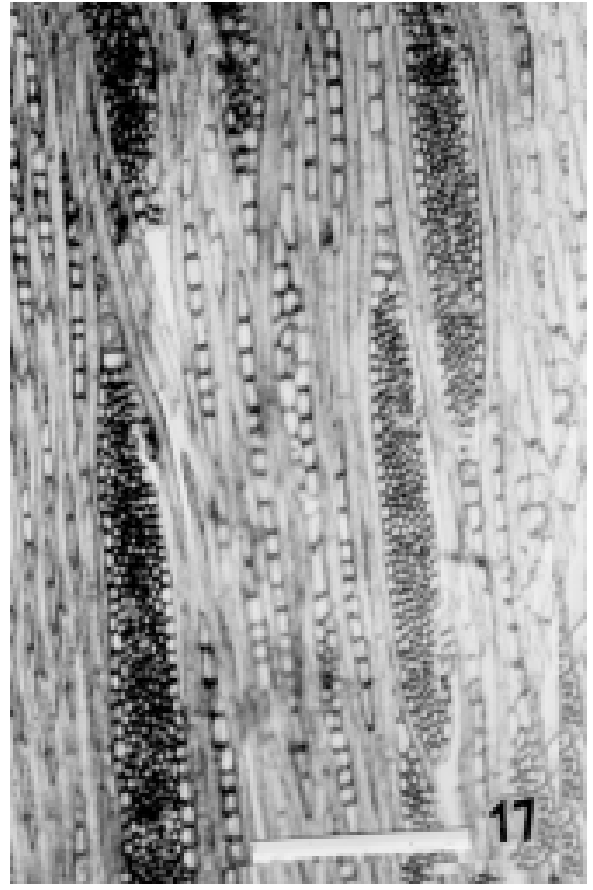

Figura 17. Sloanea grandis: corte tangencial mostrando raios multisriados (faixas escuras) e uniseriados (faixas estreitas claras); escala de $200 \mu \mathrm{m}$. 


\section{DISCUSSÃO}

Do ponto de vista tecnológico, as fibras sãos os elementos celulares constituintes da madeira mais importantes, por esta razão o conhecimento da quantidade desses elementos e de sua estrutura é de fundamental importância no que tange a qualificação de madeiras para atividades diversas. Além disso a análise dos parâmetros referentes às fibras fornece subsídios seguros no contexto de qualificação de madeiras para geração de energia e produção de papel, como se pode aferir no decorrer dessa discussão. O estabelecimento da quantidade (em percentual) das fibras, dos vasos, do parênquima axial e radial é indispensável para análise com vistas a qualificação de madeiras, tendo em vista que, quanto mais parênquima e vasos, menor será o percentual de fibras.

A fração parede e a quantidade elevada de fibras indicam se a madeira de determinada espécie pode ser usada ou não para geração de energia, como coque metalúrgico, carvão, lenha e álcool combustível, pois quanto mais alto for a fração parede, mais celulose, lignina e hemiceluloses terá a fibra, substâncias básicas geradoras de energia, portanto, madeira rica em fibras de fração parede alta, a partir de $60 \%$ e densidade igualmente alta, a partir de $600 \mathrm{~kg} /$ $\mathrm{m}^{3}$ deve ser recomendada para geração de energia. Myrocarpus frondosus e Sloanea grandis se enquadram nesta categoria. Paula (1993) e Silva Júnior et al. (1993) analisaram também a importância da fração parede no contexto de qualificação de madeiras para geração de energia. Contudo, se a fração parede for alta e a madeira como um todo tem poucas fibras, não deve ser recomendada para geração de energia. Por outro lado, o coeficiente de rigidez e o índice de Runkel das fibras são dois parâmetros anatômicos que contribuem para a qualificação de madeira de boa qualidade para produção de papel, pois quanto maior for o percentual do coeficiente de rigidez e menor o índice de Runkel, melhor será a madeira para produção de um detrminado tipo de papel (Moreschi, 1975; Foelkel \& Barrichelo, 1975; Barrichelo \& Brito, 1976; Paula \& Alves, 1997), desde que a madeira como um todo seja rica em fibras desse tipo com alto coeficiente de rigidez - acima de $50 \%$ e baixo índice de
Runkel (de 0,25 a 2,0), os quais correspondem aos grupos I, II, III e IV de Runkel, respectivamente, excelente, muito boa, boa, e regular para papel, e o grupo IV não serve para papel do ponto de vista físico, ou seja, de boa qualidade. Esses grupos podem ser aferidos na respectivas tabela de cada espécie. Nesse sentido, cada tipo de papel do ponto de vista físico, pode ser obtido com fibras indicadas pelos parâmetros mencionados. Essa indicação pode ser feita examinando o coeficiente de rigidez e o índice de Runkel das fibras da madeira de idades diferentes, a fim de aferir o ponto ideal desses dois parâmetros para produzir o tipo de papel desejado. Paula \& Alves (1997) salientam a importância do conhecimento desses dois referenciais no contexto de qualificação de madeira para produção de papel. Quanto mais fina for a parede da fibra, maior será o coeficiente de rigidez, consequentemente, o grau de colapso em função da maior flacidez. Deixa-se bem claro que uma madeira rica em vasos, parênquima axial e radial não deve ser recomendada para produção de energia e nem para papel de boa qualidade, do ponto de vista físico.

Analisando o aumento da espessura da parede das fibras do centro em direção ao alburno, deduz-se que a árvore aumenta o seu rítimo de produção de biomassa na medida em que vai se tornando mais velha, no caso, celulose, lignina e hemiceluloses, refletindo na elevação da densidade, como pode aferir na figura 1. Isso comsubstancia a verdade, segundo a qual, o estudo anatômico da madeira deve ser realizado partindo do centro em direção ao alburno. Wolcott (1983), Haygreen \& Bowyer (1989), dentre outras colocações afirmam que a densidade da madeira aumenta na medida que a árvore se torna mais velha; salientam também que a densidade do lenho juvenil é menor do que a da madeira normal em até $40 \%$. Nossos resultados indicam que a densidade do lenho juvenil é bem menor em comparação com a de outras áreas na direção radial (figura 1). Outro fato significativo diz respeito ao aumento do diâmetro dos vasos na direção do centro para o alburno, verificado nas espécies estudadas, exceto Sloanea grandis. Com relação a quantidade de vasos por $\mathrm{mm}^{2}$, constatou-se exatamente o contrário: diminuição da 
quantidade, salvo na área 4 de Eschweilera matamata e Sloanea grandis, onde verificouse aumento na direção radial centro alburno.

\section{CONCLUSÕES}

Com base nos parâmetros anatômicos determinados e analisados, bem como na densidade, chegaram-se as conclusões que se seguem:

Bellucia grossularioides, Cecropia palmata, Duguetia cauliflora, Eschweilera matamata e Parkia multijuga podem ser utilizadas para produção de papel. Myrocarpus frondosus e Sloanea grandis são recomendadas para geração de energia. A densidade da madeira das espécies estudadas aumentou do centro em direção ao alburno.

\section{BIBLIOGRAFIA CITADA}

Barrichelo, L.C.; Brito, J.O. 1976. Madeira das espécies de Eucalipto como matéria prima para a indústria de celulose e papel. Prodepef, 13:13-145.

Comissão Panamericana de Normas Técnicas. 1974. Descrição macroscópica, microscópica e geral da madeira - esquema 1 de recomendação. CPNT Assunción, $19 \mathrm{p}$.

Corrêa, A.A. 1985. Essências florestais de reflorestamento: 8 madeiras nativas da Amazônia. Acta Amazonica, 15(3/4):371402.

Corrêa, A.A.; Lobato, R.F.; Ribeiro, E.P. 1970. Estudo papeleiro de madeiras da Amazônia. Instituto Nacional de Pesquisa da Amazônia, Manaus, 36p.

Corrêa, A.A.; Ribeiro, E.B.; Luiz, CN. 1974. Estudo papeleiro de maciços florestais da Amazonia. Acta Amazonica, 4(2):23-46.

Fedalto, L. C.; Mendes, I.C.A.; Coradin, V.T.R.1989. Madeiras da Amazônia: Descrição do lenho de 40 espécies ocorrentes na floresta nacional de Tapajós. Instituto Brasileiro do Meio Ambiente e dos Recursos Naturais Renováveis, Brasília, Distrito Federal, 156p.

Foelkel, C.E.B.; Barrichelol, L.E.G. 1975.
Relações entre características de madeiras e propriedades da celulose e papel. $O$ Papel, 36:49-53.

Fontes, A.M.P.; Marques, M.H.B. 1997. Madeiras da Amazônia: Características e utilização. Instituto Brasileiro do Meio Ambiente e dos Recursos Naturais Renováveis, Brasília, 141p.

IAWA. 1989. List of microscopic features for hardwood identification. IAWA Bulletin, 10(3):221-359.

Haygreen, J.C.; Bowyer, J.L. 1989. Forest production and wood science. Segunda edição, Iowa State University Press, Ames, 500p.

INPA. 1991. Catálogo de madeiras da Amazônia: Características tecnológicas; Área da Hidrelétrica de Balbina. Instituto Nacional de Pesquisa da Amazônia, Manaus, Amazonas, 163p.

Loureiro, A.A.; Silva, M.F. 1968. Catálogo de madeiras da Amazônia. Instituto Nacional de Pesquisa da Amazônia, Manaus, Amazonas, vol.1: 433p., vol.2: 411p.

Morechi, J.C. 1975. Levantamento da qualidade da madeira em plantações artificiais de Pinus elliotii nos estados do sul do Brasil. Dissertação de Mestrado, Universidade Federal do Paraná, Curitiba Paraná, 148p.

Overbeck, W. 1968. Pastas celulósicas de madeira da Amazônia. Instituto Tecnológico de Pesquisa, São Paulo, vol. $828,31 \mathrm{p}$.

Paula, J.E. 1980. Madeiras que produzem álcool, coque e carvão. Atualidade, 72:3145.

Paula, J.E.; Alves, J.L.H. 1997. Madeiras Nativas-Anatomia, dendrologia, dendrometria, produção e uso. Instituto Brasileiro do Meio Ambiente e dos Recursos Naturais Renováveis, Brasília, $543 p$.

Paula, J.E. 1995. Anatomia e dendrometria de Mimosa artemisiana e Eucalyptus grandis. Pesq. Agropec. Bras., 30(6):745-757.

Paula, J.E. 1989. Estudo da estrutura anatômica da madeira de espécies nativas, visando seu aproveitamento na produção de energia e papel. Ciência e Cultura, 42(4):344-353. 
Paula, J.E. 1993. Madeiras da caatinga úteis para produção de energia. Pesq. Agropec. Bras., 28(2):153-165.

Runkel, R.O.H. 1952. Pulp from tropical wood. TAPP, 35(4):174-178.

Salgiya, S.C. 1972. Seasanal variation in the anatomical caracteristics of bakain wood (Melia azedrach L.) and its suitability for pulp making. Indian Pulp and Paper, Febuary/March:85-89.

Silva Júnior, F.G.; M.B.; Paula, J.E. 1993. Característica anatômica e tecnológica da madeira de Hirtella glandulosa, Hirtella gracilipes e Hirtella martiana, ocorrentes na região Centro-Oeste, visando à produção de carvão. Anais do Primeiro Congresso Florestal Pan-americano. Sociedade Brasileira de Engenheiros Florestais, Curitiba, 2:600-602.

Souza, M.H. 1997. Incentivo ao uso de novas madeiras para a fabricação de móveis. Instituto Brasileiro do Meio Ambiente e dos Recursos Naturais Renováveis, $70 \mathrm{p}$.

Wolcott, M.P. 1983. Age and thinning effects on wood properties of red spruce Technical Bulletin, 127:86-97. 